\title{
Asymmetric Information and Legislative Rules: Some Amendments
}

\author{
Vijay Krishna* \\ Department of Economics \\ Penn State University \\ University Park, PA 16802 \\ vkrishna@psu.edu
}

\author{
John Morgan* \\ Woodrow Wilson School \\ Princeton University \\ Princeton, NJ 08544 \\ rjmorgan@princeton.edu
}

March 7, 2000

\begin{abstract}
We re-examine the major tenets of the informational theory of legislative rules, focusing on the informational efficiency of rules with varying degrees of restrictiveness. When committees are heterogeneous, full efficiency is attainable under the unrestrictive open rule as well as the somewhat restrictive modified rule. In contrast, the restrictive closed rule always leads to inefficiencies. When committees are homogeneous, the situation is different. All equilibria are inefficient regardless of legislative rules. The closed rule, however, leads to greater informational efficiency than does the open rule. Further, the efficiency gains under the closed rule more than offset distributional losses regardless the degree of preference divergence. We also examine the incentives provided by the different rules for information acquisition and committee specialization.
\end{abstract}

Keywords: Legislative procedure, legislative equilibrium, costless signaling.

${ }^{*}$ We thank Doug Arnold, Tom Romer and participants at the NYU Political Economy seminar, the Princeton summer seminar, and the Caltech freeway seminar for helpful comments. The financial support of the National Science Foundation (SBR 9618648) is gratefully acknowledged. 


\section{Introduction}

It is universally acknowledged that the process of legislation can have a dramatic effect on legislative outcomes. Legislative rules determine how bills are introduced, how they are amended, and how they are voted upon. Since the middle of the nineteenth century, specialized standing committees have come to play an important role in the legislative process as almost all bills are drafted in committee before being sent to the floor for a vote. The US House of Representatives has a total of eighteen separate committees specializing in issues ranging from Agriculture to Ways and Means. Among these is the important Rules Committee that sets the rules under which each bill is considered. These rules determine whether and how the bill that emerges from a committee may be amended. Some bills are considered under the closed rule, a restrictive procedure which does not permit amendments to be offered on the floor. Others are considered under the open rule, which permits amendments to be freely offered. Currently, most bills receive some intermediate type of restrictive rule. A study by Sinclair (1995) highlights that in recent years restrictive rules have been used with increasing frequency. While only $15 \%$ of the bills in the 95th Congress were subject to restrictive rules, this proportion has risen steadily over the years; in the 102nd Congress $66 \%$ of the bills were so subject. ${ }^{1}$ A practical effect of these amendment limitations is to give considerable power to committees, ultimately guiding the final form of the bill to the House floor.

Why does the House adopt restrictive amendment procedures, thereby ceding substantial authority to the committees? Theoretical explanations can be usefully classified into two major categories and the ensuing debate between these has been referred to as the "institutional design controversy" (Sinclair (1995)). Distributive theories postulate that the legislative process is organized in a way so as to facilitate rent-extraction on the part of members. As a result, a committee is likely to be composed of a subset of the legislature with the most to gain from the actions of

\footnotetext{
${ }^{1}$ The degree of restrictiveness varies a great deal from bill to bill with the vast majority of bills being assigned to moderately restrictive "modified open" or "modified closed" rules. Completely open or completely closed bills occur much more rarely. See Sinclair (1995).
} 
the committee and restrictive rules allow the members to appropriate rents from legislation. Informational theories postulate that the role of the committee is to gather information relevant to the legislation. The legislative process itself is then a device for conveying information from the committee to the legislature and restrictive rules may be more effective at this than unrestrictive rules.

This paper undertakes a re-examination of the major tenets of informational theories.

Informational Theories In two important papers, Gilligan and Krehbiel (1987, 1989) have developed formal models that constitute the underpinnings of the informational theory. Their analysis is based on two premises, First, the gathering of information is the primary reason for the existence of specialized committees. By holding hearings and other investigations into the impact of various policies, committees obtain a degree of specialized knowledge not possessed by other members of the House. Second, the interests of the committee members are not the same as those of the median voter on the floor of the House. Thus, there is both an asymmetry of information and a divergence of preferences between the committee and the legislature. Various actions by the committee convey information to, and thus indirectly influence, the legislature. Legislative rules affect how much information transmission takes place as well as how this information is translated into policy outcomes.

Open, closed and modified (an intermediate form) legislative rules are evaluated on two grounds.

First, how effective is a particular rule in overcoming the asymmetry of information? Different rules result in different amounts of information flowing from the committee to the legislature, and the more information that flows the better it is for all parties. It is argued that rules that foster greater informational efficiency might be those that evolve in practice. ${ }^{2}$

\footnotetext{
${ }^{2} \mathrm{~A}$ rule is said to have greater informational efficiency than another if more information is transmitted from the committee to the legislature under the first rule than under the second. Put another way, the residual uncertainty faced by the legislature under the first rule is smaller than under the second.
} 
Second, how effective is a particular rule in providing the committee with the incentives to acquire relevant information? Different rules provide different incentives, and if information acquisition is costly for the committee, it may be that one set of rules leads it to acquire the information and become specialized while another set of rules does not. It is then argued that rules that foster greater specialization might be those that evolve in practice.

Main Results In this paper, we study the most informationally efficient equilibrium arising under each rule. We do this separately for the case where committee members preferences are heterogeneous (Section 3) and when they are homogeneous (Section 4). We also study the incentives to specialize (Section 5). Our findings are:

- With heterogeneous committees, the open and modified rules are fully informationally efficient, and the legislature faces no residual uncertainty (Propositions 1 and 5, below). In contrast, all legislative equilibria under the closed rule are informationally inefficient (Proposition 2).

- With homogeneous committees, the closed rule is more informationally efficient than the open rule, regardless of the divergence of preferences among the committee and the legislature (Propositions 6 and 8).

- With heterogeneous committees, the modified rule provides the best overall incentives to specialize (Section 5, below). With homogeneous committees, the closed rule provides the best overall incentives.

Related Theoretical Work The models we study were first introduced by Gilligan and Krehbiel $(1987,1989)$. One of their principal findings is that informational inefficiency is pervasive - regardless of the particular rule or the composition of the committee. When the committee is heterogeneous, they find that the closed rule is the most efficient. When the committee is homogeneous the relative efficiency of rules depends upon the degree of preference divergence between the committee and the legislature. Closed are superior to open rules if preference divergence is not too large, and the reverse is true when preference divergence is large. 
Our results differ significantly from those derived by Gilligan and Krehbiel (1987, 1989). Since the model and methodology in this paper is identical to that in Gilligan and Krehbiel $(1987,1989)$ it is worth exploring the reasons for this discrepancy.

The models that comprise the informational theory typically have multiple equilibria. Hence, a comparison of rules is then also a comparison of a single equilibrium selected for each of the rules. It is thus important that the criterion used to select a particular equilibrium be applied in a consistent manner across all rules. While Gilligan and Krehbiel (1987, 1989) have proposed maximal informational efficiency as the appropriate criterion (see Section 2 below), we show that this criterion was not applied in a consistent fashion. The results of this paper are derived by applying this criterion uniformly for each rule under consideration, and this accounts for the difference in our results and their findings. Detailed comparisons and contrasts are discussed in later sections.

Our paper is also related to Epstein (1998) who looks at equilibria arising in the Gilligan and Krehbiel (1989) model when the majority committee median has gatekeeping power and all committee members are specialized. He points out that the equilibrium selected under the open rule by Gilligan and Krehbiel (1989) is not robust to the introduction of asymmetric committees. The equilibria we analyze under the open or modified rule are not subject to this criticism.

Baron (1999) modifies the Gilligan and Krehbiel (1987) model and allows the legislature to design contracts conditional on the bill proposed by the committee. Thus, his is a screening model of legislative rules as opposed to a signalling model.

Absent any rules restrictions, the actions of the committee are just "cheap talk." Crawford and Sobel (1982) analyze a general cheap-talk model with a single sender and find that full informational efficiency cannot be attained. Battaglini (1999) studies two sender, cheap talk models in which the underlying uncertainty may be multidimensional. He introduces a model where committee members are perfectly informed only with probability $1-\varepsilon$ and examines the limiting case as $\varepsilon$ becomes small. Equilibria which are robust to such a modification are called $\varepsilon$-stable. His main result is that full informational efficiency can be achieved only when there is more than one 
dimension of uncertainty. Since the equilibria we construct under the open rule are fully efficient, they are not $\varepsilon$-stable. The full implications of $\varepsilon$-stability in the one dimensional case have still to be explored. For instance, there is no characterization of the most efficient $\varepsilon$-stable equilibrium, even under the open rule. Furthermore, how this requirement affects equilibria under restrictive rules remains an open question as well.

Austen-Smith (1990) examines the influence of legislative "cheap talk," i.e., debates, on the legislative process. He finds that debates play a significant role in setting the legislative agenda, even if they are informationally irrelevant. In a second paper, Austen-Smith (1993) examines belief formation in a setting in which the committee and the legislature have different prior distributions and these are not commonly known. He then goes on to evaluate how the process by which bills are referred to a committee can affect outcomes. Again, the issue of restrictive rules is not central to this analysis.

Restrictive legislative rules are a means of agenda control on the part of the committee. The issue of agenda control has been studied in other contexts as well. For example, Romer and Rosenthal (1979) use a model of monopoly agenda control by a budget maximizing bureaucrat to show how in these circumstances, the "median voter theorem" may not hold. Banks (1990) extends their model to a situation of asymmetric information so that only the agenda setting bureaucrat knows the "disagreement outcome" if the proposal put forward is rejected.

Shepsle and Weingast (1987) study a model which seeks to isolate the sources from which committees derive political power. They show how the legislative process confers such power to committees, highlighting the important role played by committees during the conference procedure in a bicameral legislature.

Dewatripont and Tirole (1999) examine the specialization question in a model of "advocates." While the information gathering role of an advocate is similar to that of a committee member, there are many important differences. First, the decision maker can commit to a method of directly compensating the advocates monetarily (as in Baron (1999) also). Second, the advocates are ideologically neutral: they not 
directly interested in the decision (the legislation) itself and care about it only to the extent that their reward may be contingent on the decision. Finally, the advocates are given only limited strategic power: they can either conceal the information they have acquired or reveal it truthfully. In this model, Dewatripont and Tirole (1999) show the informational benefits of heterogeneity, not of preferences, but rather of areas of specialization. One may question, however, whether a model where the legislature can, in effect, sign an optimal contract with ideologically neutral committee members and compensate them monetarily is appropriate as a model of congressional committees. Moreover, the model is silent on the effect of process, in the form of restrictive rules, on legislative outcomes.

The remainder of the paper proceeds as follows: In Section 2, we begin by sketching the informational theoretic models of legislative rules. In Section 3, we study informational efficiency for the open, modified and closed rules when committees are heterogeneous. Section 4 studies the case of a homogeneous committee, comparing the open and closed rules. In Section 5, we endogenize the specialization decision of the committee and study the efficacy of restrictive rules with both heterogeneous and homogeneous committees. In Section 6 we discuss some of the empirical implications of our results. Section 7 discusses the implications of our results for the institutional design controversy. Detailed proofs of all propositions are contained in an Appendix.

\section{The Model}

In this section, we briefly sketch the Gilligan and Krehbiel (1989) model of legislation originating in heterogeneous committees. The reader should refer to their paper for further details and motivation. In order to facilitate comparison, we adopt their notation exactly.

There are three players in the game. Initial proposals are made by two committee members, $c 1$ and $c 2$. The third player is the legislature, $\ell$, who ultimately determines the policy to be adopted. All players care about a uni-dimensional outcome $x \in X$. Each committee member has an ideal outcome, denoted by $x_{c 1}$ and $x_{c 2}$, respectively. 
The legislature's ideal outcome $x_{\ell}$ is, without loss of generality, set equal to zero. All players use "quadratic loss" utility functions to evaluate actual outcomes. Thus the legislature's utility from an outcome $x$ is

$$
u_{\ell}(x)=-\left(x_{\ell}-x\right)^{2}=-x^{2}
$$

whereas the committee members' utilities are

$$
u_{c 1}(x)=-\left(x_{c 1}-x\right)^{2} \text { and } u_{c 2}(x)=-\left(x_{c 2}-x\right)^{2},
$$

respectively. It is supposed that $x_{c 1} \geq 0$ and $x_{c 2}=-x_{c 1}$. Thus each committee member is "biased" relative to the legislature and in fact, the two members are biased in opposite directions. In what follows we write $x_{c 1}=x_{c}$ and $x_{c 2}=-x_{c}$.

The committee proposes one or more bills, $b$, and the legislature then chooses a policy $p \in P \subset \mathbf{R}$. The policy $p$ results in an uncertain outcome $x=p+\omega$ that depends on some underlying state of nature $\omega \in[0,1]$. The state of nature is assumed to be uniformly distributed and hence $\omega$ has mean $\bar{\omega}=\frac{1}{2}$ and variance $\sigma_{\omega}^{2}=\frac{1}{12}$. It is assumed that $x_{c}<3 \sigma_{\omega}^{2}=\frac{1}{4}$.

There is an exogenously given status quo policy, $p_{0}$. We suppose that $-1 \leq p_{0} \leq$ 0 so that it is not the case that the status quo policy is never optimal from the perspective of the legislature. Indeed, it is optimal if $\omega=-p_{0}$.

The sequence of moves is the following. First, nature reveals the state $\omega$ to both committee members. Second, the committee members send bills to the legislature in accordance with the rules set out below. Third, the legislature adopts a policy, again, in accordance with the rules.

Legislative Rules Three different rules governing the legislative process are considered.

1. The open rule allows both committee members $c 1$ and $c 2$ to propose bills $b_{1} \in P$ and $b_{2} \in P$, respectively. The legislature is free to choose any policy $p \in P$ it wishes. 
2. The closed rule allows committee member $c 1$ to propose a bill $b \in P$ but does not allow $c 2$ to make a proposal. Instead, $c 2$ can influence the policy only by making a speech of the form " $\omega \in[a, b] . "$ The legislature is constrained to choose from the set $\left\{b, p_{0}\right\}$, where $p_{0}$ is the status quo policy.

3. The modified rule also allows both committee member $c 1$ and $c 2$ to propose bills $b_{1}$ and $b_{2}$. The legislature is constrained to choose among the policies $\left\{b_{1}, b_{2}, p_{0}\right\}$

Strategies and Solution Concept A strategy for committee $i, b_{i}(\omega)$, specifies a bill to propose for each state. A strategy for the legislature $p\left(b_{1}, b_{2}\right)$ specifies a feasible policy for each pair of bills. Finally, the legislature forms a posterior distribution $g\left(b_{1}, b_{2}\right)$ over the state space.

We use exactly the same solution concept as Gilligan and Krehbiel $(1987,1989)$, that of legislative equilibrium, to determine the set of outcomes arising under the various rules. ${ }^{3}$ Formally, strategies and beliefs, $\left(b_{1}^{*}(\omega), b_{2}^{*}(\omega), p^{*}\left(b_{1}, b_{2}\right), g^{*}\left(b_{1}, b_{2}\right)\right)$, comprise a legislative equilibrium if

1. Legislature selects the policy that maximizes expected payoffs given beliefs.

2. Each committee member chooses $b_{i}$ to maximize payoffs given $p^{*}\left(b_{1}, b_{2}\right)$.

3. Beliefs are formed using Bayes' rule wherever possible.

Equilibrium Selection Criterion We choose the most informationally efficient equilibrium occurring under each rule. This is the natural criterion in the context of the informational theories. Indeed, Gilligan and Krehbiel (1989) write: "the primary and unique focus of the analysis is on the informational efficiency of rules" (p. 461, emphasis in original). Greater informational efficiency leads to a greater reduction in uncertainty, and so is a collective good that is unananimously preferred.

\footnotetext{
${ }^{3} \mathrm{~A}$ legislative equilibrium is the same as a perfect Bayesian equilibrium of a costless signaling game. See Banks (1991) for a detailed account of the use of signalling games in political science.
} 
It is our contention that the major implications of the informational theory to date have been derived by selecting equilibria under the different rules in an inconsistent manner. For instance, the conclusions of Gilligan and Krehbiel (1987) are based on comparing an informationally efficient equilibrium under the open rule to an informationally inefficient equilibrium under the closed rule. Likewise, the equilibria selected by Gilligan and Krehbiel (1989) for each of the rules (open, modified, and closed) are also not the most informationally efficient.

Measuring Informational Efficiency In order to obtain a measure of informational efficiency, it is useful to define the equilibrium outcome function to be:

$$
X(\omega) \equiv p^{*}\left(b_{1}^{*}(\omega), b_{2}^{*}(\omega)\right)+\omega
$$

We can then write the expected utility of the legislature as:

$$
E u_{\ell}=-\underbrace{\operatorname{Var} X}_{\text {Informational }}-\underbrace{(E X)^{2}}_{\text {Distributional }}
$$

where $\operatorname{Var} X$, the variance of the random variable $X$, represents informational losses to the floor median and $(E X)^{2}$ represents distributional losses. Likewise, for a committee member, say $c 1$, we have:

$$
\begin{aligned}
E u_{c 1} & =-E\left(x_{c}-X\right)^{2} \\
& =-\underbrace{\operatorname{Var} X}_{\text {Informational }}-\underbrace{\left(E X-x_{c}\right)^{2}}_{\text {Distributional }} .
\end{aligned}
$$

The variance in outcomes is a measure of informational efficiency and can be used to compare both different equilibria under a given legislative rule, and also, for given equilibrium selections, the rules themselves.

Homogeneous Committees The model of a homogeneous committee is identical to that above if one deletes player $c 2$ from the game. Absent $c 2$, the definitions of modified and closed rules are identical; hence only two rules (open and closed) are considered in this environment. 


\section{Heterogeneous Committees}

In this section, we compare the informational properties of the open, modified, and closed rules with heterogeneous committees.

\subsection{Open Rule}

We begin by showing that, with heterogenous committees, when no rules restrictions are in place, it is possible to obtain full informational efficiency through the bills proposed by the committee.

Before proceeding, the following definitions prove helpful. Fix an equilibrium under the open rule. Given proposals $b_{1}$ and $b_{2}$ from committee members $c 1$ and $c 2$, respectively, we will say that the two committee members agree if there exists an $\omega$ such that $b_{1}^{*}(\omega)=b_{1}$ and $b_{2}^{*}(\omega)=b_{2}$. In other words, the proposals $b_{1}$ and $b_{2}$ are

consistent with the equilibrium. If there is no such $\omega$, then the committee members are said to disagree. If there is a disagreement, then the legislature can be sure that at least one of the committee members has deviated from the equilibrium strategy.

Proposition 1 A legislative equilibrium under the open rule is

$$
\begin{gathered}
b_{1}^{*}(\omega)=-\omega \\
b_{2}^{*}(\omega)= \begin{cases}-\omega-2 x_{c} & \text { if } \omega \leq 1-2 x_{c} \\
-\omega+2 x_{c} & \text { if } \omega>1-2 x_{c}\end{cases}
\end{gathered}
$$

If $c 1$ and $c 2$ agree, then

$$
p^{*}\left(b_{1}, b_{2}\right)=b_{1} .
$$

If $c 1$ and $c 2$ disagree and $b_{1} \in[-1,0]$, then

$$
p^{*}\left(b_{1}, b_{2}\right)= \begin{cases}b_{1} & \text { if } u_{c 2}\left(b_{2}+\omega_{1}\right)>u_{c 2}\left(b_{1}+\omega_{1}\right) \\ b_{2} & \text { if } u_{c 2}\left(b_{2}+\omega_{1}\right) \leq u_{c 2}\left(b_{1}+\omega_{1}\right)\end{cases}
$$

where $\omega_{1}=-b_{1}$ and $u_{c 2}(x)=-\left(-x_{c}-x\right)^{2}$.

If $c 1$ and $c 2$ disagree, $b_{1} \notin[-1,0]$, and $b_{2} \in\left[-1,-2 x_{c}\right]$, then

$$
p^{*}\left(b_{1}, b_{2}\right)=b_{2} .
$$

Otherwise,

$$
p^{*}\left(b_{1}, b_{2}\right)=p_{0} .
$$


The beliefs of the legislature are

$$
g^{*}\left(b_{1}, b_{2}\right)=-p^{*}\left(b_{1}, b_{2}\right) .
$$

The expected utilities are

$$
\begin{aligned}
E u_{\ell} & =0 \\
E u_{c 1} & =-x_{c}^{2}=E u_{c 2}
\end{aligned}
$$

Figure 1 illustrates the open rule equilibrium identified in Proposition 1.

The strategies in Proposition 1 are quite simple and intuitive. The majority bills coincide with the legislature's ideal policy in each state. The minority bills, however, do not coincide with the ideal policy for the legislature nor are they fully revealing. If the majority and minority members agree, that is, there is a state which would result in the bills that are proposed, then the legislature infers that both are telling the truth and adopts the majority bill.

In case of a disagreement, the legislature first hypothesizes that the majority is reporting accurately. If, under this hypothesis, the minority proposal is "self-serving," in the sense that the adoption of its bill would benefit it relative to the adoption of the majority bill, then the legislature adopts the majority bill. If, under the same hypothesis, the minority proposal is not deemed to be self-serving, the legislature adopts the minority bill.

First, notice that the minority has no incentive to induce a disagreement because in exactly the circumstances when the bill it proposes is advantageous, such a bill will be viewed as being self-serving and not be adopted.

The argument that the majority also wishes to follows the equilibrium strategy is only slightly more involved. In equilibrium, the majority never prefers the minority bill to its own; thus, the majority will never induce a disagreement that leads to the adoption of the minority bill. The majority can, however, propose an alternative bill that makes the minority appear self-serving. But since the minority preferences are on the opposite side of the floor median, such a bill is even worse, if adopted, than the minority bill. In this way the legislature is able to use the opposing preferences of the minority committee member to get the majority to propose its most preferred outcome. 
In equilibrium, the majority bill is always adopted and so it seems that the minority has little influence. The minority bills have an important preventive role to play, however, since they act to discipline the majority and are the key to generating full informational efficiency. ${ }^{4}$

It is useful to contrast the fully revealing equilibrium in Proposition 1 with the partially revealing equilibrium constructed by Gilligan and Krehbiel (1989), hereafter GK, in their Proposition 1. ${ }^{5}$ To facilitate the comparison, consider an example where $x_{c}=\frac{1}{8}$. In the GK construction, the legislature is able to obtain its ideal policy only when the state is extreme, either very small $\left(\omega<\frac{1}{4}\right)$ or very large $\left(\omega>\frac{3}{4}\right)$. In intermediate states, a single default policy $\left(b=-\frac{1}{2}\right)$ is adopted. Their equilibrium is sustained as follows. When the states are extreme, both the majority and the minority propose their ideal bills, $b_{1}=-\omega+\frac{1}{8}$ and $b_{2}=-\omega-\frac{1}{8}$, respectively. Since the difference in two ideal bills is always the same $\left(b_{1}-b_{2}=\frac{1}{4}\right)$ the legislature is able to infer that they "agree." The legislature then "splits-the-difference" between these two bills by amending one of the bills to policy $-\omega$, which is also the legislature's ideal policy. In moderate states, the majority and minority propose bills chosen randomly from $\left[-\frac{7}{8}, \frac{1}{8}\right]$ and $\left[-\frac{9}{8},-\frac{1}{8}\right]$, respectively. This results in a disagreement almost always, and in that case, the legislature infers only that the state is between $\frac{1}{4}$ and $\frac{3}{4}$. It is then optimal for the legislature to adopt the default bill.

Notice that when the state is sufficiently extreme $\left(\omega<\frac{1}{4}\right.$ or $\left.\omega>\frac{3}{4}\right)$, both the minority and the majority prefer the legislature's ideal policy, $-\omega$, to the default bill, $-\frac{1}{2}$. For more moderate states $\left(\omega \in\left[\frac{1}{4}, \frac{3}{4}\right]\right)$, at least one of the committee members prefers the default bill to $-\omega$ and so chooses to send a bill at random. Thus, the legislature's ideal policy is adopted only half of the time. The (residual) variance in outcomes is $\frac{1}{96}$.

In our construction, the strategies specified in Proposition 1 require that the minority propose the bill $-\omega-\frac{1}{4}$ if $\omega \leq \frac{3}{4}$ and propose $-\omega+\frac{1}{4}$ if $\omega>\frac{3}{4}$. First, in

\footnotetext{
${ }^{4}$ It is intuitive that the minority can discipline the majority by proposing very extreme bills. In our construction, however, the minority bills are not too extreme: they all lie in within $2 x_{c}$ of the legislature's ideal policy $-\omega$.

${ }^{5}$ The reader may wish to compare our Figure 1 with Figure 1 in Gilligan and Krehbiel (1989, p. 470).
} 
every state, $\omega$, the majority always proposes the bill $-\omega$. Two key features generate full revelation in this equilibrium. First, in every state $\omega$ the majority never prefers the minority bill to $-\omega$. Second, the minority bill is not adopted if it is viewed as selfserving. In the example, a minority bill is self-serving if and only if $b_{1}>b_{2}>b_{1}-\frac{1}{4}$, that is, when the minority bill is lower than the majority bill, but not by too much. We have already provided reasons why neither member has any incentive to deviate. In equilibrium, the legislature's ideal policy is always adopted, and the (residual) variance in outcomes is 0 .

Our construction differs in several important respects. First, it is simple and intuitive. The legislature simply adopts the bill proposed by the majority while the minority bill (mostly) is biased in the direction that it favors. In the event of a disagreement, it seems natural that the legislature might try to judge the motives of the minority using the yardstick set by the majority and decide which bill to adopt on this basis. In addition, the bills proposed by the committee in our construction are neither random nor extreme, i.e., outside the set of policies that the legislature might conceivably wish to adopt, $[-1,0]$.

Second, the arguments made above do not make explicit use of the particular structure of the model. While our construction above is for the case where the committee members are symmetrically opposed to one another, it is easy to verify that a similar construction is valid for all values of $x_{c 1}$ and $x_{c 2}$ such that $x_{c 1}-x_{c 2}<\frac{1}{2}$. Moreover, it does not rely on the assumption that the distribution of states is uniform or that preferences are quadratic. Indeed, one can show that by using the self-serving yardstick to judge majority and minority bills the legislature can successfully induce full informational efficiency in a more general set-up.

A key feature of our construction is that the legislature is flexible in resolving disagreements among the committee members. That is, in the event of disagreement, the bill adopted by the legislature depends on the nature of the disagreement. This flexibility is essential to obtaining full informational efficiency.

The equilibrium described in Proposition 1 leads to the outcome 0 in every state and so it naturally follows that this is the best equilibrium for the legislature. But 
now notice that for all equilibria under the open rule, $E X=0$. This is because in any equilibrium, following any pair of bills $b_{1}, b_{2}$ the legislature must choose $p^{*}\left(b_{1}, b_{2}\right)=$ $-E\left(\omega \mid b_{1}, b_{2}\right)$, the expectation of $-\omega$ conditional on the signals. Since, in equilibrium, the beliefs are formed using Bayes' rule, this implies that $E X=0$. Thus all equilibria arising under open rules are optimal from a distributional perspective. Combining this with the efficiency properties of the equilibrium in Proposition 1 implies that it is unanimously preferred to all other equilibria arising under the open rule. Thus we have:

Corollary 1 The equilibrium described in Proposition 1 is unanimously preferred to all equilibria under the open rule.

\subsection{Closed Rule}

Next, we examine the closed rule. In the previous sub-section, we showed that under the open rule full informational efficiency can be achieved. Below, we show that the additional restrictions imposed by the closed rule preclude such outcomes. In particular, for a non-trivial interval of states, the status quo policy is chosen even though it is not the ideal policy for any of the parties.

In contrast to Proposition 1, we have:

Proposition 2 Every equilibrium under the closed rule is informationally inefficient.

The intuition for this result is that when the status quo policy coincides with the ideal policy of the majority member, he can guarantee this by proposing the bill $b=$ $p_{0}$. In other words, the majority chooses to kill the proposed legislation in committee, leaving the status quo as the only alternative available to the legislature. When the status quo policy is lower than the ideal policy for the majority, disagreement between the majority and the legislature leads the majority to also kill the bill. The reason is that it is not in the interest of the majority to propose a policy lower than the status quo, and not in the interest of the legislature to adopt a policy higher than the status quo. Hence, there is an interval where neither party gets its ideal policy. 
We next show that while informational losses are avoidable under the closed rule, distributional losses are not.

Fix an equilibrium under the closed rule. Given a bill $b$ from $c 1$ and a speech $s$ from $c 2$, we will say that the two committee members agree if there exists an $\omega$ such that $b=b^{*}(\omega)$ and $s \subseteq s^{*}(\omega)$. In other words, the bill $b$ and the speech $s$ are consistent with the equilibrium. If there is no such $\omega$ then the committee members are said to disagree. If there is a disagreement, then the legislature can be sure that at least one of the committee members has deviated from the equilibrium strategy.

Proposition 3 A legislative equilibrium under the closed rule is:

$$
\begin{aligned}
& b^{*}(\omega)= \begin{cases}-\omega & \text { if } \omega \leq-2 x_{c}-p_{0} \\
-2 \omega+\left(-2 x_{c}-p_{0}\right) & \text { if }-2 x_{c}-p_{0} \leq \omega \leq-x_{c}-p_{0} \\
p_{0} & \text { if }-x_{c}-p_{0}<\omega<x_{c}-p_{0} \\
-2 \omega+\left(2 x_{c}-p_{0}\right) & \text { if } x_{c}-p_{0} \leq \omega \leq 2 x_{c}-p_{0} \\
-\omega & \text { if } \omega \geq 2 x_{c}-p_{0} .\end{cases} \\
& s^{*}(\omega)=-b^{*}(\omega)
\end{aligned}
$$

If $c 1$ and $c 2$ agree, then

$$
p^{*}(b, s)=b .
$$

If $c 1$ and $c 2$ disagree, then

$$
p^{*}(b, s)=p_{0} .
$$

The beliefs of the legislature are

$$
g^{*}(b, s)=-p^{*}(b, s) .
$$

The expected utilities are

$$
\begin{aligned}
E u_{\ell} & =-\frac{4}{3} x_{c}^{3} \\
E u_{c 1} & =-\frac{4}{3} x_{c}^{3}-x_{c}^{2}=E u_{c 2} .
\end{aligned}
$$

Figure 2 illustrates the equilibrium described in Proposition 3.

The strategies used in Proposition 3 can be understood as follows. If both committee members prefer the ideal policy of the legislature to the status quo, then the ideal policy is proposed by the majority, supported by the minority, and adopted. If only the majority (minority) prefers the status quo to the ideal policy, then a compromise 
bill, $b$, such that the majority (minority) is indifferent between $b$ and the status quo is proposed by the majority, again supported by the minority, and adopted. If the compromise bill is worse than the status quo for either the majority or the minority, then the bill is killed in committee. A feature of the equilibrium is that all bills are supported by the minority; that is, they are "co-sponsored."

Again, it is useful to compare the equilibrium in Proposition 3 to the equilibrium under the closed rule constructed by GK. ${ }^{6}$ The two constructions are not too dissimilar, but in the GK equilibrium the majority party is able to wield its power and obtain its ideal policy a significant proportion of the time. As an example, if $x_{c}=\frac{1}{8}$ and $p_{0}=-\frac{1}{2}$, the majority's ideal policy results half of the time (when $\omega<\frac{1}{8}$ or when $\omega>\frac{5}{8}$ ) but the ideal policy of the legislature is never realized. The fact that the majority wields such power in the GK equilibrium, leads to significant distributional losses relative to our equilibrium. In addition, there are also informational losses. Continuing with the example, in the GK equilibrium, the variance of outcomes is $\frac{5}{768}$ whereas the distributional losses are $\frac{1}{256}$.

In contrast, in the equilibrium of Proposition 3, the ideal policy of the legislature is adopted half the time (when $\omega<\frac{1}{4}$ or when $\omega>\frac{3}{4}$ ) and the ideal policy of the majority is never realized. In addition, the frequency with which legislative compromise tilts in the favor of the majority is exactly the same as the frequency with which it tilts in favor of the minority. Thus, although there are distributional effects in specific instances, these effects exactly offset each other. As a result, there are no distributional losses, and the variance of outcomes is $\frac{1}{216}$. Thus on both informational and distributional grounds this equilibrium dominates the GK equilibrium.

A key feature of all equilibria under the closed rule is a substantial amount of inertia; that is, the ideal policy for the legislature must diverge widely from the status quo for any change in policy to take place. For instance, in the example studied above, there is no change in policy from the status quo for all states $\omega \in\left[\frac{3}{8}, \frac{5}{8}\right]$.

Our next result shows that from the perspective of the legislature the equilibrium

\footnotetext{
${ }^{6}$ The reader may wish to compare our Figure 2 with Figure 3 in Gilligan and Krehbiel (1989, p. 479).
} 
constructed in Proposition 3 dominates all equilibria under the closed rule.

Proposition 4 The legislative equilibrium identified in Proposition 3 is the best for the legislature among all equilibria under the closed rule.

Under the restrictive closed rule, the legislature cedes substantial power to the majority member on the committee. As Proposition 2 demonstrates, this inevitably leads to informational losses. But this need not necessarily lead to distributional losses: In the equilibrium of Proposition 3 there are none. As a consequence, the most informative equilibrium under the open or modified rule is unanimously preferred to the above equilibrium under the closed rule.

\subsection{Modified Rule}

In the previous subsections we have demonstrated that under the open rule full informational efficiency is possible (Proposition 1) and that under the closed rule it is impossible (Proposition 2). Together these seem to suggest that restrictive rules also restrict the amount of information transmitted from the committee to the legislature. Our next result shows, however, that this view is mistaken: under the restrictive modified rule, full informational efficiency can also be achieved.

Proposition 5 Fix any status quo $p_{0}$. The legislative equilibrium under the open rule described in Proposition 1 is also a legislative equilibrium under the modified rule.

Proposition 5 follows immediately from an examination of the equilibrium strategies given in Proposition 1: the strategy of the legislature always consists of a choice from the set $\left\{b_{1}, b_{2}, p_{0}\right\}$, thus conforming to the modified rule.

It is useful to contrast the restrictions on possible policies under the closed rule with those under the modified rule. Under the closed rule, in the event of a disagreement between committee members the only recourse the legislature has is to adopt the status quo. This in turn leads to the status quo "inertia" observed under the closed rule. In constrast, under the modified rule, the legislature can choose to adopt the minority proposal in the event of a disagreement. As Proposition 1 shows this additional flexibility is all that is necessary to generate full efficiency. 


\subsection{Comparing Rules}

Using the expected utility calculations in Propositions 1, 3 and 5, we obtain the following ranking among the equilibria under each of the rules:

Table 1

Legislature's Preferences over Rules

with A Heterogeneous Committee

\begin{tabular}{|ccc|}
\hline Rank & Informational & Distributional \\
\hline 1. & Open/Modified & Open/Modified/Closed \\
\hline 2. & Closed & - \\
\hline
\end{tabular}

Thus we see that, in contrast to the trade-off illustrated in Gilligan and Krehbiel (1989), the open and modified rules dominate the closed rule according to both informational and distributional criteria. Moreover, regardless of the status quo action, modified rules are just as effective as open rules and superior to completely closed rules in terms of informational efficiency, regardless of the degree of preference divergence.

\section{Homogeneous Committees}

In this section we study informational efficiency for the case where the committee's preferences are homogeneous, that is, the committee may be represented by a single pivotal actor. In this case, the modified and closed rules are the same as one another. Hence, we compare only the open and closed rules.

\subsection{Open Rule}

Under the open rule, Gilligan and Krehbiel's (1987) model is isomorphic to the costless signalling model of Crawford and Sobel (1982). In this model, all legislative equilibria arising under the open rule have only a finite number of equilibrium policies (see Lemma 1 of Crawford and Sobel, 1982) and thus are informationally inefficient. 
Corollary 2 Every equilibrium under the open rule with a homogeneous committee is informationally inefficient.

Theorem 3 of Crawford and Sobel (1982) characterizes the most informationally efficient equilibrium under the open rule with homogeneous committees. For future reference, we state this as

Proposition 6 The most informationally efficient equilibrium under the open rule with a homogeneous committee results in the following expected utilities:

$$
\begin{aligned}
& E u_{\ell}=-\frac{1}{12 N^{2}}-\frac{x_{c}^{2}\left(N^{2}-1\right)}{3} \\
& E u_{c}=-\frac{1}{12 N^{2}}-\frac{x_{c}^{2}\left(N^{2}-1\right)}{3}-x_{c}^{2}
\end{aligned}
$$

where $N$ is the smallest positive integer greater than or equal to $\left(-\frac{1}{2}+\frac{1}{2} \sqrt{1+\frac{2}{x_{c}}}\right)$.

As is the case under open rules with heterogeneous committees, none of the equilibria entail distributional losses. Thus the equilibrium that is most informationally efficient is also unanimously preferred by all parties.

\subsection{Closed Rule}

We compare the information content under the open rule relative to the closed rule. First, notice that Proposition 2 holds as well for a homogeneous committee.

Proposition 7 Every equilibrium under the closed rule with a homogeneous committee is informationally inefficient.

Since both open and closed rules lead to informational inefficiencies, it remains to examine the informativeness of equilibria under the closed rule as compared to the open rule.

Proposition 8 Suppose $3 x_{c} \leq-p_{0} \leq 1-x_{c}$. With a homogeneous committee a legislative equilibrium under the closed rule is:

$$
b^{*}(\omega)= \begin{cases}-\omega+x_{c} & \text { if } 0 \leq \omega \leq-3 x_{c}-p_{0} \\ 4 x_{c}+p_{0} & \text { if }-3 x_{c}-p_{0} \leq \omega \leq-2 x_{c}-p_{0} \\ 2 x_{c}+p_{0} & \text { if }-2 x_{c}-p_{0}<\omega<-p_{0} \\ p_{0} & \text { if }-p_{0} \leq \omega \leq x_{c}-p_{0} \\ -\omega+x_{c} & \text { if } x_{c}-p_{0} \leq \omega \leq 1\end{cases}
$$




$$
p^{*}(b)= \begin{cases}b & \text { if } b \notin\left(p_{0}, 2 x_{c}+p_{0}\right) \cup\left(2 x_{c}+p_{0}, 4 x_{c}+p_{0}\right) \\ p_{0} & \text { otherwise }\end{cases}
$$

The beliefs of the legislature are

$$
g^{*}(b)=\left\{\begin{array}{ll}
x_{c}-b & \text { if } 4 x_{c}+p_{0}<b \leq x_{c} \\
U\left(\left[-3 x_{c}-p_{0},-2 x_{c}-p_{0}\right]\right) & \text { if } b=4 x_{c}+p_{0} \\
U\left(\left[-2 x_{c}-p_{0},-p_{0}\right]\right) & \text { if } b=2 x_{c}+p_{0} \\
U\left(\left[-p_{0},-p_{0}+x_{c}\right]\right) & \text { if } b=p_{0} \\
x_{c}-b & \text { if }-1+x_{c} \leq b<p_{0} \\
-p_{0} & \text { otherwise }
\end{array} .\right.
$$

The expected utilities are

$$
\begin{aligned}
E u_{\ell} & =-\frac{4}{3} x_{c}^{3}-x_{c}^{2} \\
E u_{c} & =-\frac{4}{3} x_{c}^{3}
\end{aligned}
$$

The intuition for this result is that when the legislature's ideal policy diverges substantially from the status quo, the legislature is willing to cede power to the committee and exchange distributional losses for informational gains. In these circumstances, the committee proposes its own ideal policy and, confronted with the choice between this and the status quo the legislature adopts the proposed bill. When the legislature's ideal policy is close to the status quo, the committee is no longer able to force the legislature to accede to its demands. The situation becomes much more complex and in equilibrium, the committee proposes one of three policies. In particular, when the status quo lies between the legislature's ideal policy and the committee's ideal policy, no compromise can be reached and hence no new policy is adopted.

This equilibrium is similar to the one constructed by Gilligan and Krehbiel (1987, Proposition 5). Their construction differs in that for states between $-p_{0}-3 x_{c}$ and $-p_{0}+x_{c}$ only two policies are chosen. As a consequence, the informational efficiency of the equilibrium in Proposition 8 is higher than in the GK equlibrium. At the same time the distributional losses in the two equilibria are the same. As a result, the equilibrium derived here is unanimously preferred to the GK equilibrium. More concretely, consider the case where $x_{c}=\frac{1}{8}$ and $p_{0}=-\frac{1}{2}$. The distributional losses in both the GK equilibrium and the equilibrium in Proposition 8 amount to $\frac{1}{64}$. The 
equilibrium in Proposition 8 is superior on informational grounds, however, with informational losses of $\frac{1}{384}$ compared to losses of $\frac{1}{96}$ in the GK equilibrium.

\subsection{Comparison of Rules}

An explicit characterization of the most informative legislative equilibrium under the closed rule with a homogeneous committee appears to be difficult. In particular, we do not know whether the equilibrium in Proposition 8 is the most informative or not. Nevertheless, a comparison shows that for all values of $x_{c}<\frac{1}{4}$, this closed rule equilibrium is more informative than any equilibrium under the open rule. Further, the following proposition shows that this equilibrium is preferred by the legislature to any equilibrium under the open rule. Formally,

Proposition 9 Suppose $x_{c}-1 \leq-p_{0} \leq 3 x_{c}$. With a homogeneous committee, the equilibrium in Propostition 8 is informationally superior to all open rule equilibria. Further, all open rule equilibria are worse for the legislature than the equilibrium in Proposition 8.

The conclusion of Proposition 9 alters the results of Gilligan and Krehbiel (1987). In their paper, they find the closed rule is superior to the open rule if and only if the committee is not composed of "preference outliers," that is, $x_{c}$ is not too large. With preference outliers, the distributional losses to the legislature exceed any informational gains in selecting the closed rule over the open rule. We find that the potential informational gains under the closed rule are, in fact, greater than in the Gilligan and Krehbiel (1987) equilibrium. As a consequence, informational gains always more than offset distributional losses and, as a result, the closed rule is superior even with preference outliers. We summarize these findings in Table 2. 
Table 2

Legislature's Preferences over Rules

With A Homogeneous Committee

\begin{tabular}{|cccc|}
\hline Rank & Informational & Distributional $^{7}$ & Overall \\
\hline 1. & Closed & Open & Closed \\
\hline 2. & Open & Closed & Open \\
\hline
\end{tabular}

\section{Specialization}

So far we have compared the informational efficiency of different legislative rules under the assumption that committee members are informed. An additional basis for comparing rules is the incentives each rule provides for the committee to become informed about the implications of policies on outcomes. Gathering information is expensive: a committee's staff has to do research, cost-benefit studies have to be conducted, hearings have to be held, and so on. Since legislative rules differ in the efficiency and distributional gains accruing to the committee, it may well be the case that under one rule, a committee chooses to become informed whereas under another rule, it does not. Clearly, the efficiency losses when a committee chooses to remain uninformed are likely to be severe. To study these effects, we examine the efficiency and distributional gains from specialization under each rule for heterogeneous and homogeneous committees.

Homogeneous Committees With specialized committees, we showed that closed rules lead to greater efficiency as well as distributional gains to the committee as compared to the open rule. When the committee is unspecialized, equilibria under both rules are equally inefficient. Moreover, the committee obtains no distributional gains under the open rule. When the status quo reflects the fact that the legislature is completely uninformed, i.e. $p_{0}=-\frac{1}{2}$, then there are no distributional gains to

\footnotetext{
${ }^{7}$ Since the distributional losses under the open rule are zero, the losses under the best legislative equilibrium will always be (weakly) larger.
} 
the committee under the closed rule as well. Thus, the closed rule provides a strictly greater incentive to specialize than does the open rule. This is not to say that the committee will specialize whenever it is socially desirable to do so. Since efficiency gains accrue to both the committee and the legislature, the committee's specialization decision does not take into account all of the social gains in comparing the benefits and costs of specialization. Thus, there are circumstances where it is socially desirable for the committee to specialize, but it will choose not to do so. Moreover, since the committee's decision to specialize also takes into account distributional gains to itself, but not distributional losses to the legislature, there will also be circumstances where a committee will choose to specialize even though it is socially undesirable to do so. Thus, although a closed rule provides the best incentives to specialize, it does not align private and social incentives to do so.

Heterogeneous Committees We now turn to heterogeneous committees. Here the exact nature of the process by which committee members become informed affects the incentives to specialize. It is useful to distinguish two cases. If the information is acquired publicly as a result of committee hearings or committee wide staff reports, then both members of the committee are informed. On the other hand, if information is acquired privately as a result of reports from staff working exclusively for either the majority or minority then it is possible that one member of the committee is informed whereas the other is not.

Public Information When information is publicly acquired, the decision to become specialized is a committee-wide decision; that is, either all members of the committee are specialized or none are. As we showed previously, equilibria with specialized committees under the open, modified, and closed rules do not differ in their distributional characteristics (indeed, all three rules lead to no distributional gains to either the majority or minority committee member); however, the open and modified rule lead to greater efficiency gains compared to the closed rule. In contrast, when a committee is unspecialized, all three rules lead to the same level of efficiency losses; however, the rules differ in their distributional components. Under the open 
or modified rule, there are no distributional gains; whereas under the closed rule, there may be distributional gains to the majority. Regardless of the level of these gains, the open and modified rule provide strictly greater incentives to specialize than the closed rule. This happens because there are greater efficiency gains under the open or modified rule, and the committee suffers no reductions in distributional gains relative to the unspecialized case. Since distributional effects are absent under the open and modified rules, it is never the case that a committee receiving these rules will choose to specialize even when it is socially undesirable to do so. Of course, since the committee's specialization decision does not account for the full efficiency gains accruing to society, it is still the case that it may be socially desirable to specialize, but the committee will choose not to do so.

Private Information When information is privately acquired, the decision to specialize is taken separately by the majority and minority members.

First, consider the majority's specialization decision. If the majority anticipates that the minority will remain unspecialized, the strategic situation is the same as that under a homogeneous committee. Moreover, the closed and modified rules are identical in this situation. ${ }^{8}$ We previously established that in this case, closed and modified rules provide better specialization incentives than open rules. Next, suppose that the majority anticipates that the minority will become informed. If the majority remains unspecialized then, under the closed rule, this coincides with the case where both members are unspecialized. The modified and open rules correspond to the closed and open rule in the homogeneous case, respectively, but where the committee's preferences reflect the minority. As preference divergence grows large, the adverse distributional effects associated with giving power to the minority dominate; hence the modified rule provides the best incentives to specialize. When preferences are less divergent, the relatively larger efficiency gains associated with the closed rule dominate, and it provides the best incentives to specialize.

Now consider the minority's specialization decision. If it specializes and antici-

\footnotetext{
${ }^{8} \mathrm{We}$ continue to assume that $p_{0}=-\frac{1}{2}$.
} 
pates that the majority will remain unspecialized, then the closed rule provides no benefit. The modified and open rules correspond to the homogeneous committee closed and open rules, respectively. Thus, the modified rule provides the greatest incentive to specialize. Next, suppose that the minority anticipates that the majority will become informed. If the minority remains unspecialized, then, under the closed or modified rules, this coincides with a closed rule in the homogeneous case. Likewise, the open rule coincides with the homogeneous case as well. When preference divergence is large, the distributional losses from the modified rule dominate, and it provides the best incentives to specialize. When preference divergence is relatively small, then the large efficiency gains of the open rule dominate, and it provides the best incentives.

To recapitulate, the modified rule provides the best incentives for both members of the committee to specialize when preferences are divergent (calculations show that this requires $\left.x_{c}>0.15\right)$. When preferences are less divergent, there is a trade-off among the rules. The closed rule provides the best incentives for the majority to specialize; whereas the open rule provides the minority with the best incentives. How this is resolved, of course, depends on the relative costs of the different committee members in becoming specialized.

\section{Empirical Implications}

What are the empirical implications of the informational theory and is the theory consistent with data on rules assignment in the House? There has been a lively debate regarding these questions (Krehbiel (1991); Sinclair (1995); Dion and Huber (1996); Dion and Huber (1997); Krehbiel (1997a); and Krehbiel (1997b)). In this section we revisit some of the issues raised in these papers and examine the consequences of our results.

At the most general level, the theory postulates that restrictive rules are more likely to be observed when the legislature's expected utility in equilibrium is greater under, say a closed rule as compared to an open rule. A weak postulate of the 
informational theory thus relates the probability of observing a restrictive rule to the difference in payoffs resulting from using such a rule. More precisely,

$$
\text { Prob }[\text { closed }]=f\left(E u_{l}^{\text {closed }}-E u_{l}^{\text {open }}\right)
$$

where $f$ is an increasing function. Expected utilities, of course, cannot be observed in the data but the theory indicates relationships between other observable variables and the difference in expected utilities. One such variable is the degree of preference divergence, $x_{c}$ and the other is the degree of heterogeneity in committee preferences.

Reduced form models in this area typically seek to explain the occurence of restrictive rules by using, among others, explanatory variables that measure (or act as a proxy for) preference divergence and heterogeneity.

The different models of the informational theory lead to differing predictions about how $x_{c}$ affects the difference in utilities, $\Delta_{l} \equiv E u_{l}^{\text {closed }}-E u_{l}^{\text {open }}$, and then via (2), the probability that a restrictive rule will be used..$^{9}$ As we show below, heterogeneity plays an important role in the predictions of the effects of preference outliers.

In the case of a heterogeneous committee, our results predict that the relationship between the difference in utilities and the preference divergence $x_{c}$ is unambiguously negative (more precisely, $\frac{\partial}{\partial x_{c}}\left(\Delta_{l}\right)<0$, for all $x_{c}$ ). This, combined with (2), has the implication that one should expect to see restrictive rules more often in circumstances when $x_{c}$ is small. In other words, outliers should be given less restrictive rules. In the case of a homogeneous committee, $\frac{\partial}{\partial x_{c}}\left(\Delta_{l}\right)<0$, if and only if $x_{c}$ is small (precisely, if $\left.x_{c}<\frac{1}{12}\right)$.

In almost all the models estimated by Krehbiel (1991), Dion and Huber (1997) and Krehbiel (1997a), the preference divergence variable has a significant negative effect. This finding does not seem to be affected by alternative measures preference divergence: continuous $\left(x_{c}\right)$ or binary (outlier). The only exception is that in some models estimated by Dion and Huber (1996), the effect of the outlier variable is

\footnotetext{
${ }^{9}$ In practice it is unrealistic to expect an exact measurement of $x_{c}$. Rather, in many cases, a binary classification is developed depending on whether $x_{c}$ is above or below some threshold value. If $x_{c}$ is large, and hence preference divergence is substantial, the committee is classified as consisting of outliers.
} 
insignificant.

In addition to the effect of heterogeneity on the relation between preference divergence and restrictiveness, our results predict that the gain from using a restrictive closed rule versus an open rule is greater when committees are homogeneous rather than heterogeneous, that is, $\Delta_{l}^{\text {hom }}>\Delta_{l}^{\text {het }}$. This prediction should, however, be treated with some care since it involves holding the degree of preference divergence $x_{c}$ fixed. Thus, it involves a comparison between a homogeneous committee with preference parameter $x_{c}$ and a heterogeneous committee where the majority and minority have preference parameters $x_{c}$ and $-x_{c}$, respectively. The somewhat restrictive nature of this prediction means that it is rather difficult to submit this to a convincing empirical test.

Empirical evidence on how heterogeneity variables affect rule assignments is mixed. The signs of the effects seem to depend closely on how heterogeneity and preference divergence are measured. Dion and Huber (1997) interact binary outlier and heterogeneity measures and find that heterogeneity is generally associated with less restrictive rules. Krehbiel $(1991,1997 \mathrm{a})$ uses continuous measures of both preference divergence and heterogeneity and finds the opposite effect, although for several specifications, the effect of heterogeneity is not statistically significant. For our purposes, an ideal empirical test would combine a continuous measure of divergence with a discrete heterogeneity measure.

The informational theory is also suggestive of the view that the greater the degree of specialization of a committee, the more likely it is to receive restrictive rules. As our results show, however, this hypothesis is sensitive to whether the committee is heterogeneous or not. Homogeneous specialized committees should receive closed rules whereas heterogeneous specialized committees should receive modified rules.

Overall, the empirical evidence is not inconsistent with these predictions. The proxy variables used for specialization, the number of laws cited by the committee and the seniority of its members, are generally associated with more restrictive rules. Krehbiel $(1991,1997 \mathrm{a})$ also finds that the specialization variables have generally positive effects but these are not always statistically significant. Sinclair (1995) finds that 
"laws cited" has a positive and significant effect. Dion and Huber (1997) also find that "laws cited" is positive and significant, whereas the committee seniority variable has a negative but insignificant coefficient.

Other Implications for Empirical Work Our paper highlights the importance in distinguishing between somewhat restrictive modified rules and more restrictive closed rules. We showed in Proposition 5 that modified rules are fully informationally efficient in sharp contrast to closed rules. Moreover, when committees are heterogeneous, the modified rule provides the best overall incentives for the committee to specialize.

All of the existing empirical studies of which we are aware, however, give no special distinction to modified rules - a bill is coded as either restrictive (closed) or not. Indeed, in the coding convention followed by most researchers, modified rules (as studied here) and closed rules are lumped together into one category. Our results suggest that intermediate degrees of restrictiveness can matter a great deal to informational efficiency. This suggests that the conclusions regrading the empirical support for informational theories may depend on whether modified rules are coded as restrictive or not. In our view, it would be useful to recode rule-bill observations in such a way as to distinguish between unrestrictive open rules, somewhat restrictive modified rules, and more restrictive closed rules.

\section{Discussion}

In this section we return to the so-called institutional design controversy. Two rival theories, the distributive and informational, seek to explain the design of legislative institutions.

The distributive theory, as expounded by, for instance, Weingast and Marshall (1988) postulates that the committee system is set-up to facilitate the exchange of influence over policy choices. Legislators effectively bid for membership in committees which have jurisdiction over issues they perceive as being most important for their 
reelection. Appointment to a particular committee, say Agriculture or Banking, endows the members with "rights" to influence policy in that area and the seniority system preserves those rights. Committee members appropriate rents in their areas of interest; thus the resulting outcomes may be socially inefficient. Restrictive rules that limit the power of the legislature to amend proposed bills allow the committee members to appropriate the rents they are "due" by virtue of their appointments.

The key difference is that the distributive theory views the committee system as a means of rent appropriation and exchange whereas the informational theory views the committee system as a means of specialization and information transmission. Committee composition reflects this difference. In particular, distributive theories predict that committees are more likely to be composed of preference outliers and receive restrictive rules. Our analysis indicates that preference divergence, per se, is not harmful to informational efficiency. With heterogeneous committees, full efficiency can be achieved under open or modified rules regardless of preference divergence. Thus, significant preference divergence, as predicted by the distributive theory, need not have harmful informational effects provided rules are not too restrictive.

The distributive theories also predict that committees are likely to be composed of members with similar (homogeneous) preferences. The informational theory predicts that homogeneous committees are associated with informational losses. Thus there is a trade-off between the between a committee optimally composed for distributive purposes and one composed for informational purposes.

In some instances, the legislature may be able to overcome this trade-off by making multiple referrals to separate committees. This requires that two homogeneous committees with opposing preferences have jurisdiction over the bill. In that case, a system of multiple referrals to two homogeneous committees is strategically equivalent to a system of a single referral to one heterogeneous committees. As long as the rules permit the legislature the choice between the bills proposed by the two committees, mimicking the modified rule, full informational efficiency can be achieved.

The informational theory shows not only that full efficiency can be achieved, but that it can be achieved in a way that ensures that there are no distributional costs. 
In other words, the members of the committee are unable to extract any rents from the legislative process; the policy outcomes are those most favored by the legislature. Now, under the open rule, the legislature retains all power to amend bills, and so it is not too surprising that the committee is unable to appropriate any rents. Under the modified rule, however, the legislature cedes substantial power to the committee and yet that despite this, the committee is still unable to appropriate any rents. As explained earlier, the equilibrium constructed in Proposition 1 exploits the fact that committee preferences are opposed; the preferences of the majority and minority committee members straddle those of the legislature. ${ }^{10}$ This allows the legislature to extract all the information in a way that the chosen bill is always one that comes out of the committee; and this is true both in and out of equilibrium. Put another way, the committee is unable to exploit its power under the modified rule because positive rents to one side mean negative rents to the other. Even though the modified rule is restrictive, the fact that it allows both sides to propose bills gives the legislature enough strategic flexibility to play-off one against the other so that full efficiency can be achieved. In contrast, the restrictive closed rule allows only the majority to propose bills, leaving the legislature with almost no room to maneuver. As a result, under the closed rule, full efficiency cannot be achieved.

\section{A Proofs of Propositions}

\section{A.1 Proof of Proposition 1}

We show that none of the players can gain by deviating from the prescribed strategies.

Note that the legislature is always optimizing given its beliefs and these beliefs are consistent with Bayes' rule along the equilibrium path. So we only need to consider deviations by $c 1$ and $c 2$.

We will say that $c 2$ 's proposal is self-serving if $u_{c 2}\left(b_{2}+\omega_{1}\right)>u_{c 2}\left(b_{1}+\omega_{1}\right)$, where

\footnotetext{
${ }^{10}$ The fact that they are symmetrically opposed and hence exactly balance each other is not important. Propositions 1 and 5 continue to hold even if committee preferences are asymmetric. What is important is that they lie on either side of the legislature's preferences.
} 
$\omega_{1} \equiv b_{1}^{*-1}\left(b_{1}\right)=-b_{1}$. In other word, $c 2$ 's proposal is self-serving if $b_{2}$ is more profitable for $c 2$ than $b_{1}$ under the hypothesis that $c 1$ is "telling the truth" and hence the state is $\omega_{1}=-b_{1}$. It is easy to verify that $b_{2}$ is self-serving if and only if $b_{1}>b_{2}>b_{1}-2 x_{c}$.

First, suppose $c 2$ follows the prescribed strategy. We argue that $c 1$ has no profitable deviations.

If $\omega \leq 1-2 x_{c}$ but $c 1$ deviates to a $b_{1}$ such that $b_{1}>b_{1}^{*}(\omega)$, then $c 2$ 's proposal is not viewed as self-serving and hence the resulting policy $b_{2}^{*}(\omega)$ is even lower than $-\omega$. This is disadvantageous for $c 1$. If $c 1$ deviates to a $b_{1}$ such that $b_{1}<b_{1}^{*}(\omega)$ then whether $c 2$ 's proposal will be viewed as self-serving or not depends on $b_{1}$. If it is viewed as self-serving, then the chosen policy is $b_{1}<b_{1}^{*}(\omega)$ which is worse for $c 1$. If it is viewed as not being self-serving, then the chosen policy is $b_{2}^{*}(\omega)=-\omega-2 x_{c}$ which is also lower than $-\omega$.

If $\omega>1-2 x_{c}$ but $c 1$ deviates to a $b_{1}$ such that $b_{1}>b_{1}^{*}(\omega)$, then the policy chosen is at least as high as $b_{2}^{*}(\omega)$ and since $b_{2}^{*}(\omega)$ is already too high, this is not advantageous for $c 1$. If $c 1$ deviates to a $b_{1}$ such that $b_{1}<b_{1}^{*}(\omega)$, then $c 2$ 's proposal is not viewed being as self-serving and hence $b_{2}^{*}(\omega)=-\omega+2 x_{c}$ is adopted. But $c 1$ is exactly indifferent between this bill and the equilibrium bill $-\omega$ and so such a deviation is not advantageous either.

Now suppose $c 1$ follows the prescribed strategy but $c 2$ deviates. The only circumstance in which this could be profitable, that is when $u_{c 2}\left(b_{2}, \omega\right)>u_{c 2}\left(b_{1}^{*}(\omega), \omega\right)$, results in no change to the chosen policy. Thus $c 2$ has no profitable deviation.

Finally, it is unprofitable for $c 1$ to deviate to a bill $b_{1}$ that is outside the range of equilibrium actions.

\section{A.2 Proof of Proposition 2}

Suppose the contrary, so that for every pair $\left(b^{*}(\omega), s^{*}(\omega)\right)$, the legislature chooses the policy $b^{*}(\omega)=-\omega$.

Define $\left[\omega_{0}, \omega_{1}\right]$ to be the interval such that for all $\omega \in\left[\omega_{0}, \omega_{1}\right],-\left(x_{c}-\left(p_{0}+\omega\right)\right)^{2} \geq$ $-\left(x_{c}\right)^{2}$. It is routine to verify that $\omega_{0}=-p_{0}$ and $\omega_{1}=2 x_{c}-p_{0}$. Hence, in this interval, $c 1$ prefers the status quo action to the equilibrium action. But now for $\omega \in\left(\omega_{0}, \omega_{1}\right)$, 
if $c 1$ chooses $b^{\prime}=-\omega+\varepsilon$, where $\varepsilon>0$ is small, then $\ell$ must either choose policy $p_{0}$ or $b^{\prime}$. Since both of these policies are preferred to the equilibrium action by $c 1$, this is a profitable deviation.

\section{A.3 Proof of Proposition 3}

We show that no one can gain by deviating from the prescribed strategies.

First, note that the legislature is always optimizing given its beliefs and the beliefs are consistent with Bayes' rule along the equilibrium path. So we only need to consider deviations by $c 1$ and $c 2$.

A. $\omega \leq-2 x_{c}-p_{0}$. If $c 1$ deviates, this results in a policy $p_{0}$ which is lower than $-\omega$ and hence worse from $c 1$ 's perspective.

If $c 2$ deviates, resulting in $p_{0}$. This is not profitable since $x_{c} \leq-x_{c}-\omega-p_{0}$ and thus $-x_{c}^{2} \geq-\left(-x_{c}-\omega-p_{0}\right)^{2}$.

B. $-2 x_{c}-p_{0} \leq \omega \leq-x_{c}-p_{0}$. If $c 1$ deviates, this results in policy $p_{0}$ which is lower than $-\omega$, and again, worse from $c 1$ 's perspective.

If $c 2$ deviates, this, by construction, leads to exactly the same utility for $c 2$ as the equilibrium action. To see this notice that $-2 \omega+\left(-2 x_{c}-p_{0}\right)-\left(-x_{c}-\omega\right)=$ $\left(-x_{c}-\omega\right)-p_{0}$, and so his utilities from the two outcomes are the same.

C. $-x_{c}-p_{0} \leq \omega \leq x_{c}-p_{0}$. In this region a deviation by neither $c 1$ nor $c 2$ affects the policy chosen, $p_{0}$.

D. $x_{c}-p_{0} \leq \omega \leq 2 x_{c}-p_{0}$. If $c 1$ deviates, then by construction, this leads to exactly the same utility for $c 1$ as the equilibrium action. To see this notice that $\left(x_{c}-\omega\right)-\left(-2 \omega+\left(2 x_{c}-p_{0}\right)\right)=p_{0}-\left(x_{c}-\omega\right)$ and so his utilities from the two outcomes are the same.

If $c 2$ deviates, this results in a policy $p_{0}$ which is higher than $-\omega$ and hence worse from $c 2$ 's perspective. 
E. $\omega \geq 2 x_{c}-p_{0}$. The proof is analogous to the case where $\omega \leq-2 x_{c}-p_{0}$.

The calculation of the expected utilities is routine.

\section{A.4 Proof of Proposition 4}

The proof of Proposition 4 is somewhat involved. This is because unlike the open or modified rules, the closed rule does not permit full informational efficiency (Proposition 2) and so a detailed examination of the set of equilibria is needed.

We begin by identifying a parametric class of closed rule equilibria that includes the equilibrium of Proposition 3. This proves useful in determining the most informative equilibrium.

Lemma 1 For each $\alpha \in\left[0, x_{c}\right]$, the following constitutes a legislative equilibrium under the closed rule:

$$
\begin{aligned}
& b^{\alpha}(\omega)= \begin{cases}-\omega & \text { if } \omega \leq-2 x_{c}-p_{0} \\
-2 \omega+\left(-2 x_{c}-p_{0}\right) & \text { if }-2 x_{c}-p_{0} \leq \omega \leq-x_{c}-p_{0}-\alpha \\
p_{0}+2 \alpha & \text { if }-x_{c}-p_{0}-\alpha<\omega<x_{c}-p_{0}-\alpha \\
p_{0} & \text { if } x_{c}-p_{0}-\alpha \leq \omega \leq x_{c}-p_{0} \\
-2 \omega+\left(2 x_{c}-p_{0}\right) & \text { if } x_{c}-p_{0} \leq \omega \leq 2 x_{c}-p_{0} \\
-\omega & \text { if } \omega \geq 2 x_{c}-p_{0} .\end{cases} \\
& s^{\alpha}(\omega)=\left\{\begin{array}{l}
\text { if } \omega \leq-x_{c}-p_{0}-\alpha \\
\omega \in\left[-x_{c}-p_{0}-\alpha, x_{c}-p_{0}-\alpha\right] \quad \text { if }-x_{c}-p_{0}-\alpha \leq \omega \leq x_{c}-p_{0}-\alpha \\
-p_{0} \\
\omega
\end{array} \quad \text { if } x_{c}-p_{0}-\alpha<\omega<x_{c}-p_{0}\right.
\end{aligned}
$$

If $c 1$ and $c 2$ agree or $b=p_{0}+2 \alpha$, then

$$
p^{\alpha}(b, s)=b
$$

If $c 1$ and $c 2$ disagree and $b \neq p_{0}+2 \alpha$, then

$$
p^{\alpha}(b, s)=p_{0}
$$


The beliefs of the legislature are

$$
g^{\alpha}\left(b_{1}, b_{2}\right)= \begin{cases}-p^{\alpha}(b, s) & \text { if } b \neq p_{0}+2 \alpha \\ {\left[-x_{c}-p_{0}-\alpha, x_{c}-p_{0}-\alpha\right]} & \text { otherwise }\end{cases}
$$

The expected utilities are

$$
\begin{aligned}
E u_{\ell} & =-\frac{4}{3} x_{c}^{3}-2 \alpha^{2} \\
E u_{c 1} & =-\frac{4}{3} x_{c}^{3}-x_{c}^{2}+4 \alpha x_{c}\left(2 x_{c}-\alpha\right) \\
E u_{c 2} & =-\frac{4}{3} x_{c}^{3}-x_{c}^{2}-4 \alpha x_{c}\left(2 x_{c}-\alpha\right)
\end{aligned}
$$

See Figure 3 for an illustration of a semi-revealing equilibrium of type $\alpha$.

Proof of Lemma 1 The proof of Lemma 1 is virtually identical to the proof of Proposition 3. There are two differences however. The first is that it is now possible for $c 1$ to deviate and induce the policy $p_{0}+2 \alpha$. If $\omega \leq-x_{c}-p_{0}-\alpha$, this deviation induces a lower policy than that called for in equilibrium; hence the equilibrium policy is preferred by $c 1$. for $\omega \geq x_{c}-p_{0}-\alpha$, such a deviation induces a policy that is higher than $p_{0}$ and, in this region, the policy $p_{0}$ is preferred by $c 1$ to all actions higher than $p_{0}$; hence this is not a profitable deviation. Next, consider deviations in the region $\left[-x_{c}-p_{0}-\alpha, x_{c}-p_{0}-\alpha\right]$. To show that no deviations are possible in this region observe that at the point $\omega=x_{c}-p_{0}-\alpha$, committee member $c 1$ is exactly indifferent between the policy $p_{0}+2 \alpha$ and the status quo $p_{0}$. For states $\omega$ in this region satisfying, $\omega<x_{c}-p_{0}-\alpha, c 1$ strictly prefers $p_{0}+2 \alpha$ to $p_{0}$ and for states $\omega>x_{c}-p_{0}-\alpha, c 1$ strictly prefers $p_{0}$ to $p_{0}+2 \alpha$. Thus no deviations from the equilibrium strategies are profitable in this region also.

The calculation of the expected utilities is then routine.

For further reference we will refer to the equilibria identified in Lemma 1 as semirevealing equilibria of type $\alpha$.

Two observations are worth noting. First, a semi-revealing equilibrium of type 0 is identical to the equilibrium in Proposition 3 (Figure 3 reduces to Figure 2 when 
$\alpha=0$.) Second, the legislature's payoff is maximized when $\alpha=0$, that is, the equilibrium in Proposition 3 is the at least as good for the legislature as any semirevealing equilibrium of type $\alpha$.

We now show that, in fact, the equilibrium in Proposition 3 is the best for the legislature among all equilibria. We do this by showing that from the perspective of the legislature, any other equilibrium is dominated by some semi-revealing equilibria of type $\alpha$. As noted above, this in turn is dominated by the equilibrium in Proposition 3. In order to establish this formally, some definitions will prove useful.

Suppose $(\bar{b}, \bar{s}, \bar{p})$ is some arbitrary legislative equilibrium under the closed rule. Let $\bar{P}$ denote the resulting equilibrium policy function; that is, for all $\omega, \bar{P}(\omega)=$ $\bar{p}(\bar{b}(\omega), \bar{s}(\omega))$.

It is also useful to define $q_{1}(\omega)$ to be the policy such that in state $\omega$, committee member $c 1$ is exactly indifferent between $q_{1}(\omega)$ and $p_{0}$. In other words, $q_{1}(\omega)$ satisfies: $-\left(x_{c}-q_{1}(\omega)-\omega\right)^{2}=-\left(x_{c}-p_{0}-\omega\right)^{2}$ and from this it follows that $q_{1}(\omega)=-2 \omega+$ $2 x_{c}-p_{0}$. In any state $\omega$, the set of policies that $c 1$ considers to be at least as good as $p_{0}$ are those lying between $\min \left\{p_{0}, q_{1}(\omega)\right\}$ and $\max \left\{p_{0}, q_{1}(\omega)\right\}$.

Lemma 2 Suppose $\bar{P}$ is an equilibrium policy function $\bar{P}$ under the closed rule. Then for almost all $\omega$,

$$
\min \left\{p_{0}, q_{1}(\omega)\right\} \leq \bar{P}(\omega) \leq \max \left\{p_{0}, q_{1}(\omega)\right\}
$$

Proof. If there exists an open interval of states where neither of the above conditions are satisfied then $c 1$ can profitably deviate by proposing $b=p_{0}$ in these states, guaranteeing that $p_{0}$ will be adopted.

Lemma 2 sets some limits on equilibrium policy function $\bar{P}$ determined by the fact that $c 1$ 's incentive constraints must be respected. Similarly, $c 2$ 's incentive constraints must also be respected. Committee member $c 2$, however, is in a much weaker position than $c 1$ since he can only make speeches and not offer proposals. Whereas proposals constrain the legislature's choices under the closed rule speeches are only "cheap talk" and can be ignored by the legislature. 
We will say that $c 2$ 's speech is relevant given proposal $b$ if there exists an $s^{\prime}$ such that $p\left(b, s^{\prime}\right)=p_{0}$ and an $s^{\prime \prime}$ such that $p\left(b, s^{\prime \prime}\right)=b$. In other words, given $c 1$ 's proposal $b, c 2$ 's speech can affect the policy adopted. If $c 2$ cannot affect the policy, that is, if $p(b, s)$ is a constant no matter what speech $s c 2$ makes, we will say that $c 2$ 's speech is irrelevant.

Analogous to the definition above, define $q_{2}(\omega)$ to be the policy such that in state $\omega$, committee member $c 2$ is exactly indifferent between $q_{2}(\omega)$ and $p_{0}$. In other words, $q_{2}(\omega)$ satisfies: $-\left(-x_{c}-q_{1}(\omega)-\omega\right)^{2}=-\left(-x_{c}-p_{0}-\omega\right)^{2}$ and from this it follows that $q_{2}(\omega)=-2 \omega-2 x_{c}-p_{0}$. In any state $\omega$, the set of policies that $c 2$ considers to be at least as good as $p_{0}$ are those lying between $\min \left\{p_{0}, q_{2}(\omega)\right\}$ and $\max \left\{p_{0}, q_{2}(\omega)\right\}$.

Lemma 3 Suppose $\bar{P}$ is an equilibrium policy function under the closed rule. Then for almost all $\omega$, if c2's speech is relevant given proposal $\bar{b}(\omega)$,

$$
\min \left\{p_{0}, q_{2}(\omega)\right\} \leq \bar{P}(\omega) \leq \max \left\{p_{0}, q_{2}(\omega)\right\}
$$

Proof. If there exists an open interval $O$ of states in which $c 2$ 's speech is relevant given proposal $\bar{b}(\omega)$, then for any $\omega \in O$, there exists a speech $s^{\prime}(\omega)$ such that $p\left(b(\omega), s^{\prime}(\omega)\right)=p_{0}$. If $p_{0}$ is preferred to $\bar{P}(\omega)$ by $c 2$, he can profitably deviate by making the speech $s^{\prime}(\omega)$.

Lemma 4 Suppose $\bar{P}$ is an equilibrium policy function under the closed rule. If there is an open interval of states $O$ such that $\bar{P}(\cdot)$ is continuous and strictly decreasing (or strictly increasing) over $O$, then either

1. $c 2$ 's speech is relevant given proposal $b(\omega)$; or

2. $\bar{P}(\omega)=-\omega+x_{c}$.

Proof. Suppose that the contrary is true. Then there exists some open interval $O$ where the policy function is strictly decreasing (say), speeches are irrelevant, and $\bar{P}(\omega) \neq-\omega+x_{c}$. In this case, in any state $\omega \in O, c 1$ prefers either policy $\bar{b}(\omega-\varepsilon)$ or $\bar{b}(\omega+\varepsilon)$ for small enough $\varepsilon$ to the equilibrium policy $\bar{b}(\omega)$ since $\bar{P}(\omega) \neq-\omega+x_{c}$. 
Moreover, since speeches are irrelevant, $c 1$ can unilaterally induce either of these policies in state $\omega$, and this is a profitable deviation.

Suppose that neither of the above conditions given in Lemma 4 holds over some open interval of states $\omega \in O$. Then it must be the case that $\bar{P}(\omega)$ is almost everywhere a constant function. Moreover, at any point $\omega^{\prime}$ where $\lim _{\omega \rightarrow \omega^{\prime}}^{-} P(\omega)=p^{-} \neq$ $p^{+}=\lim _{\omega \rightarrow \omega^{\prime}}^{+} P(\omega)$, then $c 1$ must be indifferent between $p^{+}$and $p^{-}$in state $\omega^{\prime}$. We shall refer to an equilibrium policy function having these properties as a step function over the interval $O$.

Lemma 5 Given any equilibrium under the closed rule there exists a semi-revealing equilibrium of type $\alpha$ that is no worse for the legislature.

Proof. Suppose $\bar{P}$ is an equilibrium policy function under the closed rule. Let $\left(b^{\alpha}, s^{\alpha}, p^{\alpha}\right)$ be a semi-revealing equilibrium of type $\alpha$, and similarly, let $P^{\alpha}$ denote the resulting policy function; that is, for all $\omega, P^{\alpha}(\omega)=p^{\alpha}\left(b^{\alpha}(\omega), s^{\alpha}(\omega)\right)$.

We will argue that there exists an $\alpha \in\left[0, x_{c}\right]$ such that the legislature's payoff from $P^{\alpha}$ is at least as large as its payoff from $\bar{P}$. Again, it is useful to divide the state space into different regions.

A. $\omega \leq-2 x_{c}-p_{0}$ or $\omega \geq 2 x_{c}-p_{0}$.

If $\omega \leq-2 x_{c}-p_{0}$ then $P^{\alpha}(\omega)=-\omega$ and this is the best possible policy for the legislature. Similarly, if $\omega \geq 2 x_{c}-p_{0}$ then again $P^{\alpha}(\omega)=-\omega$, the optimal policy for the legislature.

B. $x_{c}-p_{0} \leq \omega \leq 2 x_{c}-p_{0}$

Now suppose $x_{c}-p_{0} \leq \omega \leq 2 x_{c}-p_{0}$. In this region, $P^{\alpha}(\omega)=q_{1}(\omega)=-2 \omega+$ $2 x_{c}-p_{0} \geq-\omega$ and thus has the property that all policies that the legislature prefers to $P^{\alpha}(\omega)$ are lower than $P^{\alpha}(\omega)$. Also, $q_{1}(\omega) \geq p_{0}$ and hence by Lemma $2, \bar{P}(\omega) \geq$ $P^{\alpha}(\omega)$. Hence, $P^{\alpha}(\omega)$ is no worse for the legislature than $\bar{P}(\omega)$.

C. $-x_{c}-p_{0} \leq \omega \leq x_{c}-p_{0}$.

Lemma 2 implies that $\bar{P}(\omega) \geq p_{0}$ in this region. Combining this with Lemma 3 implies that in any legislative equilibrium, speeches are irrelevant in this region. By 
Lemma 4, it then follows that any equilibrium $\bar{P}$ must either be a step function or $\bar{P}(\omega)=-\omega+x_{c}$. However, $\bar{P}(\omega)=-\omega+x_{c}$ is not possible since the legislature prefers $p_{0}$ to $-\omega+x_{c}$ for every $\omega$ in this region, and thus can guarantee $p_{0}$. Thus, $\bar{P}$ is a step function in this region.

Suppose that the last discontinuity in the region $\left[-x_{c}-p_{0}, x_{c}-p_{0}\right]$ occurs at the point $\omega^{\prime}$ and let $\lim _{\varepsilon>0} \bar{P}\left(\omega^{\prime}-\varepsilon\right)=p^{\prime}$. First, notice that at $\omega^{\prime}, c 1$ must be indifferent between the $p^{\prime}$ and $p_{0}$ (since speeches by $c 2$ must be irrelevant in this region). This is same as saying that $p^{\prime}=q_{1}(\omega)=-2 \omega^{\prime}+2 x_{c}-p_{0}$.

Next, we claim that if the region in which $p^{\prime}$ is the equilibrium action under $\bar{P}$ is $\left[\sigma^{\prime}, \omega^{\prime}\right]$ then it must be the case that $P^{*}\left(\sigma^{\prime}\right)=p^{\prime}$. A necessary condition for this to be an equilibrium is that given that it knows only that $\omega \in\left[\sigma^{\prime}, \omega^{\prime}\right]$ the legislature weakly prefers to choose $p^{\prime}$ rather than $p_{0}$. Given its information, the legislature's optimal policy is $-\frac{1}{2}\left(\sigma^{\prime}+\omega^{\prime}\right)$ and it chooses $p^{\prime}$ as long as

$$
p^{\prime}+\frac{1}{2}\left(\sigma^{\prime}+\omega^{\prime}\right) \leq-\frac{1}{2}\left(\sigma^{\prime}+\omega^{\prime}\right)-p_{0}
$$

which is equivalent to

$$
\sigma^{\prime} \leq \omega^{\prime}-2 x_{c}
$$

and this in turn is equivalent to saying that $\sigma^{\prime} \leq P^{*-1}\left(p^{\prime}\right)$.

Now notice that since $\omega^{\prime} \in\left[-x_{c}-p_{0}, x_{c}-p_{0}\right]$ there exists an $\alpha \in\left[0, x_{c}\right]$ such that $\omega^{\prime}=x_{c}-p_{0}-\alpha$ and hence $\sigma^{\prime} \leq-x_{c}-p_{0}-\alpha$. Finally, since $c 1$ is indifferent between $p^{\prime}$ and $p_{0}$ at the point $\omega^{\prime}=x_{c}-p_{0}-\alpha$, it must be that $p^{\prime}=p_{0}+2 \alpha$. However, this is identical to a $P^{\alpha}$ equilibrium in this region.

D. $-2 x_{c}-p_{0} \leq \omega \leq-x_{c}-p_{0}$.

In any subinterval of this region, if $\bar{P}(\omega)>P^{*}(\omega)$, then by Lemmas 3 and $4, \bar{P}$ must consist of either a step function or follow $c 1$ 's bliss line. From the argument given in region $\mathbf{C}$, we know that for all $\omega \geq-x_{c}-p_{0}-\alpha$ where $\alpha \in\left[0, x_{c}\right], \bar{P}(\omega)=p_{0}+2 \alpha$.

Next note that any equilibrium which has the property that for all $\omega \geq-x_{c}-p_{0}-$ $\alpha, \bar{P}(\omega) \geq p_{0}+2 \alpha$ or $P(\omega)<-2 \omega+\left(-2 x_{c}-p_{0}\right)$ is worse than any $P^{\alpha}$ equilibrium from the perspective of the legislature. It is routine to verify that any equilibrium $\bar{P}$ consisting of either a step function or $\bar{P}(\omega)=-\omega+x_{c}$ or both has the property that 
$\bar{P}(\omega) \geq p_{0}+2 \alpha$ or $P(\omega)<-2 \omega+-2 x_{c}-p_{0}$. Hence $P^{\alpha}$ is no worse than $\bar{P}$ in this region.

It is now easy to verify that $\bar{P}$ is no better for the legislature than some $P^{\alpha}$.

Combining Lemmas 1 and 5 together with the observation that from the perspective of the legislature the best semi-revealing equilibrium of type $\alpha$ is one where $\alpha=0$, completes the proof of Proposition 4.

\section{A.5 Proof of Proposition 8}

Proof. First, observe that the beliefs are consistent with Bayes' rule wherever possible. Next, we show that given beliefs, the legislature cannot profitably deviate.

1. If $4 x_{c}+p_{0}<b \leq x_{c}$, then by selecting the policy $b$, the legislature earns $-x_{c}^{2}$. By deviating to $p_{0}$, the legislature earns $\left(b-p_{0}\right)\left(p_{0}+2 x_{c}-b\right)-x_{c}^{2}$ and, since $4 x_{c}+p_{0}<b$, this expression is less than $-x_{c}^{2}$.

2. If $b=4 x_{c}+p_{0}$, then the expected utility of the legislature from playing $b$ is $-\frac{7}{3} x_{c}^{3}$. By deviating to $p_{0}$, the legislature earns $-\frac{19}{3} x_{c}^{3}$, so deviating is clearly not profitable.

3. If $b=2 x_{c}+p_{0}$, the legislature earns $-\frac{8}{3} x_{c}^{3}$ by playing $b$. By deviating to $p_{0}$, the legislature's payoffs are identical, so this is not a profitable deviation.

It is routine to verify that deviation is unprofitable to the legislature for the remaining cases.

We now turn to the incentives of the committee to deviate.

1. If $0 \leq \omega \leq-3 x_{c}-p_{0}$, then the committee is obtaining its best possible outcome so deviation is not profitable.

2. Suppose $-3 x_{c}-p_{0} \leq \omega \leq-2 x_{c}-p_{0}$. The committee is just indifferent between the policy $4 x_{c}+p_{0}$ and $2 x_{c}+p_{0}$ if and only if $\omega=-2 x_{c}-p_{0}$. Hence, for all $\omega \geq-2 x_{c}-p_{0}$, the committee prefers the policy $4 x_{c}+p_{0}$ to any policy $p \leq 2 x_{c}+p_{0}$.

The remaining cases are analogous to one of the ones above. 


\section{A.6 Proof of Proposition 9}

It is sufficient to show that the legislature's expected utility in the equilibrium under the closed rule constructed in Proposition 8 is higher than the legislature's expected utility in the best equilibrium under the open rule, that is, in the equilibrium described in Proposition 6.

Under the open rule, the payoff to the legislature in the best legislative equilibrium is (Proposition 6)

$$
-\frac{1}{12 N\left(x_{c}\right)^{2}}-\frac{x_{c}^{2}\left(N\left(x_{c}\right)^{2}-1\right)}{3}
$$

where $N\left(x_{c}\right)$ is the smallest positive integer greater than or equal to $\left(-\frac{1}{2}+\frac{1}{2} \sqrt{1+\frac{2}{x_{c}}}\right)$ and, in fact, is the number of distinct policies chosen in equilibrium.

This can be equivalently stated as follows. For any positive integer $N$ define $x(N)=\frac{1}{2 N(N+1)}$. If $x(N) \leq x_{c}<x(N-1)$ then $N\left(x_{c}\right)=N$.

Under the closed rule, the payoff to the legislature in the equilibrium constructed in Proposition 8 is

$$
-\frac{4}{3} x_{c}^{3}-x_{c}^{2}
$$

Now since $x_{c}<\frac{1}{4}, N\left(x_{c}\right) \geq 2$ and so

$$
-x_{c}^{2} \geq-\frac{x_{c}^{2}\left(N\left(x_{c}\right)^{2}-1\right)}{3}
$$

Next note that for any $N \geq 2$ and $x(N) \leq x_{c}<x(N-1)$

$$
\begin{aligned}
-\frac{4}{3} x_{c}^{3} & >-\frac{4}{3} x(N-1)^{3} \\
& =-\frac{4}{3}\left(\frac{1}{2 N(N-1)}\right)^{3} \\
& =-\frac{1}{6 N^{3}(N-1)^{3}} \\
& \geq-\frac{1}{12 N^{2}}
\end{aligned}
$$

Thus the second term in (4) is no less than the corresponding term in (3) and the first term is actually greater. 


\section{References}

[1] Austen-Smith, David. 1990. "Information Transmission in Debate." American Journal of Political Science 34: 124-152.

[2] Austen-Smith, David. 1993. "Interested Experts and Policy Advice; Multiple Referrals under Open Rule." Games and Economic Behavior 5: 3-43.

[3] Banks, Jeffrey S. 1990. "Monopoly Agenda Control with Asymmetric Information." Quarterly Journal of Economics 105: 445-464.

[4] Banks, Jeffrey S. 1991. Signalling Games in Political Science. Chur, Switzerland: Harwood Academic Publishers.

[5] Baron, David P. 1999. "Legislative Organization with Informational Committees." Research Paper No. 1572, Graduate School of Business, Stanford University, July.

[6] Crawford, Vincent P. and Joel Sobel. 1982. "Strategic Information Transmission." Econometrica 50: 1431-1451.

[7] Dewatripont, Matthias and Jean Tirole. 1999. "Advocates." Journal of Political Economy 107: 1-39.

[8] Dion, Douglas D. and John D. Huber. 1996. "Procedural Choice and the House Committee on Rules." Journal of Politics 58: 25-53.

[9] Dion, Douglas D. and John D. Huber. 1997. "Sense and Sensibility: The Role of Rules." American Journal of Political Science 41: 945-957.

[10] Epstein, David. 1998. "Partisan and Bipartisan Signaling in Congress." Journal of Law, Economics, and Organization 14: 183-204.

[11] Gilligan, Thomas W., and Keith Krehbiel. 1987. "Collective Decision-Making and Standing Committees: An Informational Rationale for Restrictive Amendment Procedures." Journal of Law, Economics, and Organization 3:287-335. 
[12] Gilligan, Thomas W., and Keith Krehbiel. 1989. "Asymmetric Information and Legislative Rules with a Heterogeneous Committee." American Journal of Political Science 33: 459-490.

[13] Krehbiel, Keith. 1991. Information and Legislative Organization. Ann Arbor: University of Michigan Press.

[14] Krehbiel, Keith. 1997a. "Restrictive Rules Reconsidered." American Journal of Political Science 41: 919-944.

[15] Krehbiel, Keith. 1997b. "Rejoinder to 'Sense and Sensibility'." American Journal of Political Science 41: 958-964.

[16] Romer, Thomas, and Howard Rosenthal. 1979. "Bureaucrats vs. Voters: On the Political Economy of Resource Allocation by Direct Democracy." Quarterly Journal of Economics 93: 563-588.

[17] Shepsle, Kenneth A., and Barry R. Weingast. 1987. "The Institutional Foundations of Committee Power." American Political Science Review 81: 85-104.

[18] Sinclair, Barbara. 1995. "House Special Rules and the Institutional Design Controversy." In Kenneth A. Shepsle and Barry R. Weingast (eds.), Positive Theories of Congressional Institutions, Ann Arbor: University of Michigan Press.

[19] Weingast, Barry R. and William Marshall. 1988. "The Industrial Organization of Congress." Journal of Political Economy 96: 132-163. 


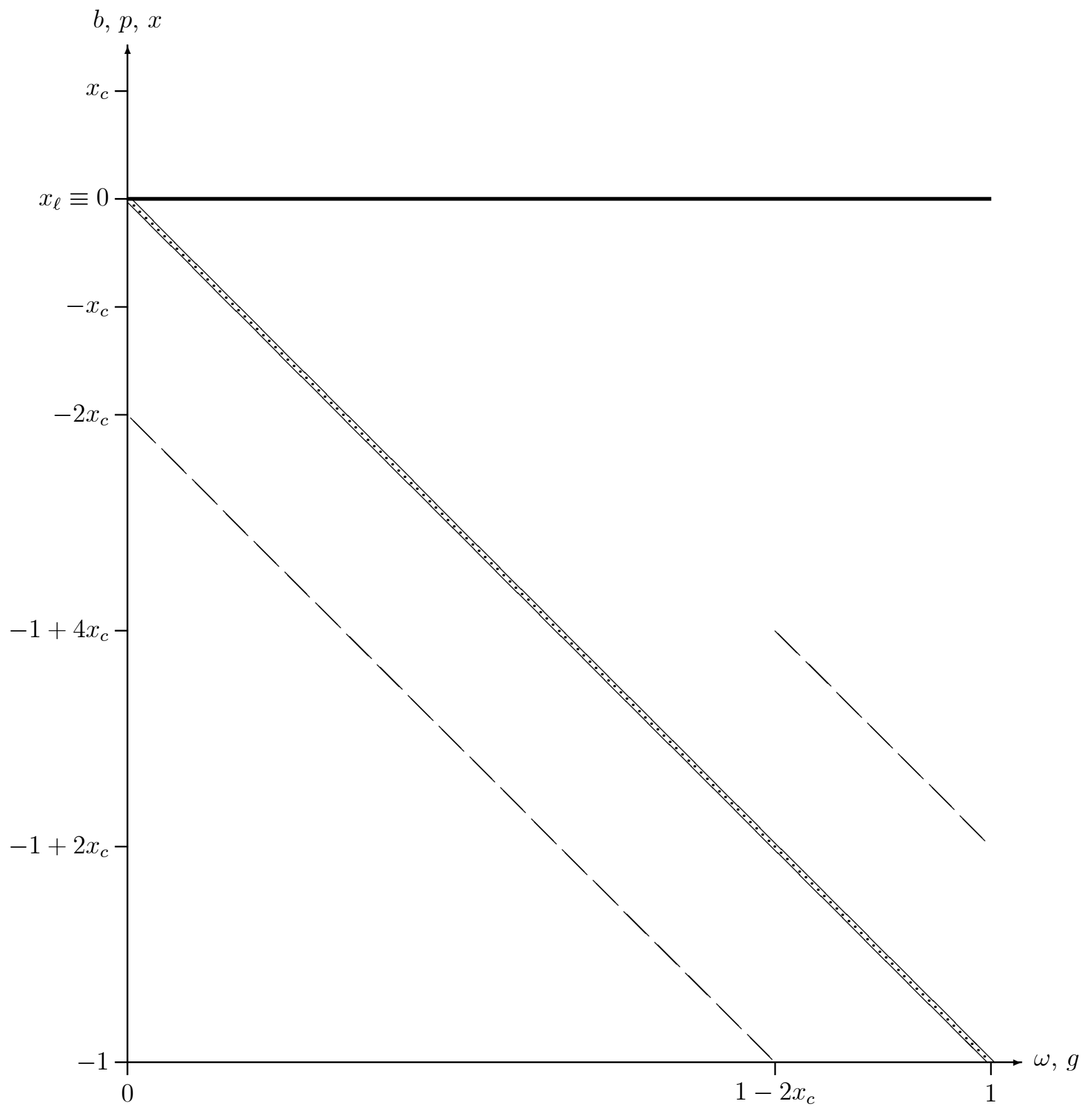

KEY:

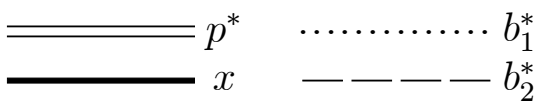

Figure 1: An Informationally Efficient Equilibrium under the Open Rule 


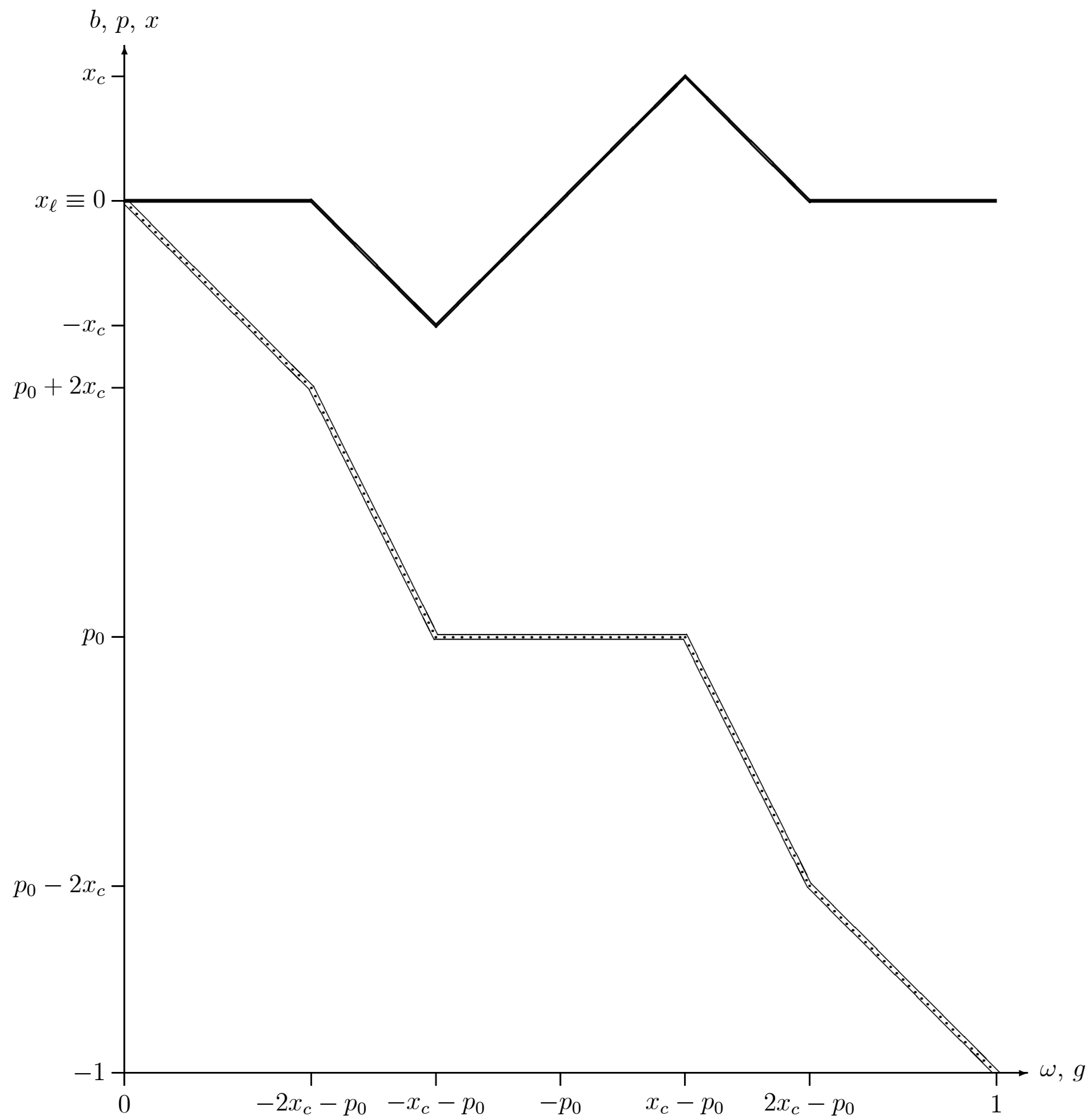

KEY :

…........ $b^{*}$

$\overline{=} p^{*}$

$x$

Figure 2: An Equilibrium under the Closed Rule 


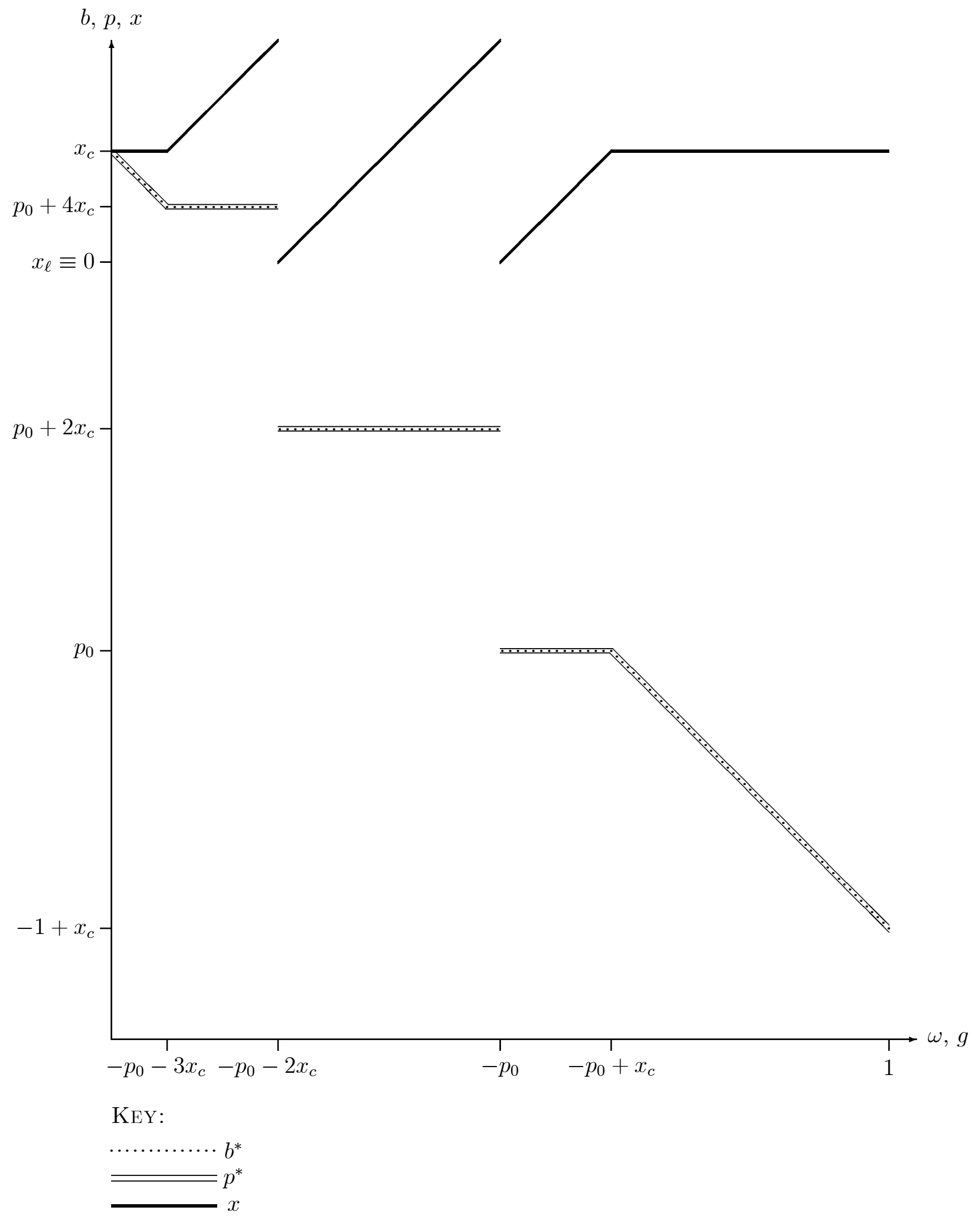

Figure 3: An Equilibrium under the Closed Rule with a Homogeneous Committee 46 


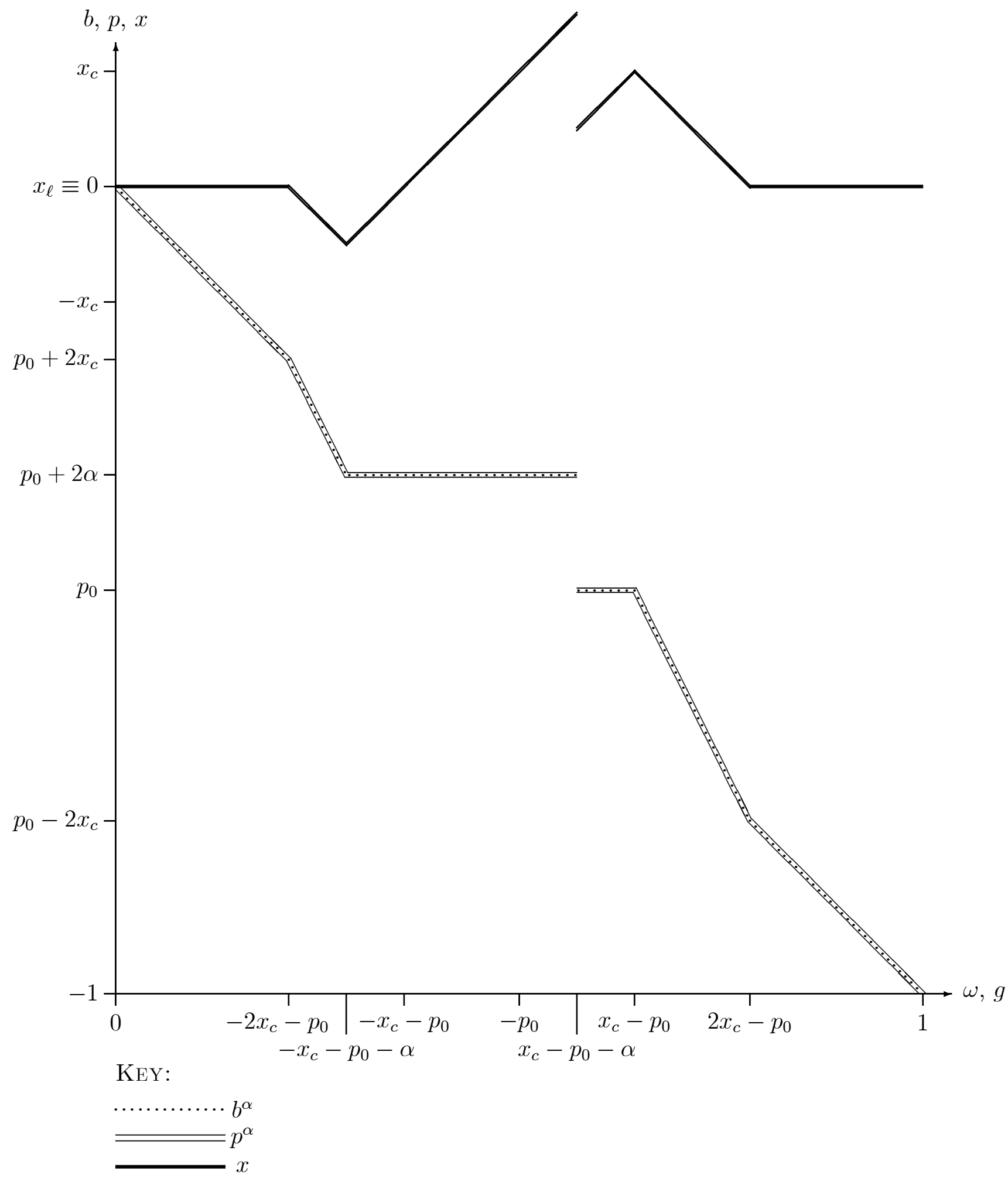

Figure 4: A Semi-Revealing Equilibrium of Type $\alpha$ under the Closed Rule 